\title{
CURCUMIN NANOPARTICLES VERSUS CURCUMIN IN AMELIORATION OF INFLAMMATORY AND PATHOLOGICAL CHANGES DURING THE MIGRATORY PHASE OF MURINE TRICHINELLOSIS
}

\author{
By
}

AMANY F. ATIA ${ }^{1}$, NOHA A. ABOKHALIL ${ }^{1}$, DINA M. SWEED ${ }^{2}$, INAS M. MOAZ ${ }^{3}$, And NOHA M. ABOU HUSSIEN ${ }^{* *}$

Department of Medical Parasitology, Faculty of Medicine ${ }^{1}$ and Department of

Pathology ${ }^{2}$ and Department of Epidemiology, Preventive Medicine ${ }^{3}$, National Liver

Institute, Menoufia University, Shebin El-Kom, Menoufia Governorate, Egypt

( ${ }^{*}$ Correspondence: dr_nohaabohussein@yahoo.com).

Abstract

Trichinella spiralis can cause systemic inflammatory manifestations all over the body before habituating their destination in the striated muscles. Its new borne larvae (NBL) most dangerous phase go via bloodstream of different organs during migration.

This study explored the anti-inflammatory, antioxidant and anti-apoptotic effects of Curcumin (Cur) and Curcumin nanoparticles (Cur-Nano) on inflammatory and pathological changes occurred in different organs in murine trichinellosis during larval migratory phase.

Forty (40) male Swiss albino mice were divided into four groups of ten mice each. GI: mice infected and treated with Cur, GII: mice infected and treated with Cur-Nano, GIII: infected nontreated mice (positive control) and GIV: non-infected non-treated (negative control). Mice were infected orally with $200 \mathrm{~T}$. spiralis larvae per mouse. GI \& GII received treatment on $13^{\text {th }}$ day post infection (dpi) for 5 successive days. All mice were sacrificed on the $30^{\text {th }}$ dpi. Effects of Cur $\&$ Cur-Nano were evaluated by counting $T$. spiralis encysted larvae in muscle by light microscope. Frozen sera $\left(-20^{\circ} \mathrm{C}\right)$ were used for quantitative estimation of ALT, AST, TNF $\alpha$, transforming growth factor- $\beta$ (TGF- $\beta$ ) and Troponin (Trop). Specimens of lung, liver, brain and heart were fixed in neutral buffered formalin for $\mathrm{H} \& \mathrm{E}$ and immunohistochemical staining.

The results showed that number of encysted $T$. spiralis larvae in GI \& GII was significantly reduced compared to GIII. In both treated groups (GI \& GII), there was a significant reduction in mean levels of AST, ALT, TNF $\alpha$, TGF- $\beta$, \& Trop. There was significant improvement of bile duct injury and proliferation, alveolar and pleural inflammation, and bronchial epithelial proliferation, as well as improvement of degenerative changes in brain and heart. The infected nontreated group (GIII) showed significant overexpression of Cyclooxygenase-2 $\left(\mathrm{COX}_{2}\right)$, caspase 3 , glial fibrillary acidic protein (GFAP), arginase and granzyme $b$, with a significant low expression of peroxisome proliferator-activated receptors (PPARs) as compared to treated groups.

Keywords: Curcumin, Curcumin-nanoparticles, Trichinella spiralis, Migrating NBL, Anti-inflammatory, Antioxidant, Antiapoptotic.

\section{Introduction}

Trichinellosis is a cosmopolitan zoonotic infectious disease caused by Trichinella spiralis, with economic problem in swine production and food safety (Bruschi et al, 2019). Infection occurs after ingestion of infected undercooked pork meat. Stomach acidity causes ex-cystation of the ingested larvae that invade the epithelial lining of the upper part of the small intestine to mature into adult worms. Within 2-3 weeks, fertilized females produce NBL that are carried out via blood and lymphatic systems to invade different organs and later encapsulate in the cardiac and skeletal striated muscles (Saad et al, 2016). Trichinellosis was divided into 3 clinical phases, intestinal invasion by the adult worms in the enteral phase, migration of NBL in the migratory phase and encystment of larvae in the parenteral phase (Despommier, 1993).

Trichinella spiralis NBL migration is considered the most dangerous phase of infection, during which there is a generalized extensive immune-inflammatory reaction resulting from the high antigenicity of the larvae (Pozio, 2007). They can cause systemic inflammatory manifestations all over the 
body before habituating their final destination (Saad et al, 2018).

The lung is one of the main organs for the retention and destruction of NBL (Bruschi et al, 1992). Larval migration through the lung provokes an inflammatory allergic response together with bronchus associated-lymphoid tissue (BALT) and goblet cell hyperplasia (Venturiello et al, 2007). Farid et al. (2019) observed acute hepatitis in response to infection with $T$. spiralis in rats. Saad et al. (2018) reported that trichinellosis caused a cerebrovascular disease in $10-20 \%$ of patients. Moreover, cardiac and cerebral affections are the most fatal complications in this phase (Pozio et al, 2019).

Upon infection with $T$. spiralis, mice showed an innate and adaptive immune response to limit tissue injury and to reduce immune-mediated inflammation caused by migrating NBL, however, this response facilitates the intracellular infection by $T$. spiralis (Huang et al, 2014). In the migratory phase of trichinellosis, a severe immune stimulation is triggered by the presence of adult worms in the intestine and the larvae (whether the free NBL in the circulation or the incompletely encysted larvae in the muscles) leading to the release of a large amount of pro-inflammatory cytokines and oxidative stress products (Saad et al, 2018). Moreover, activation of macrophages during $T$. spiralis infection may lead to the production of TNF- $\alpha$ and IFN- $\gamma$, which has been reported to be effective for killing some parasites, such as Leishmania (Lopes et al, 2014). In a reverse action, TNF- $\alpha$ in combination with IFN- $\gamma$ can activate murine macrophages for the elimination of parasitic infections (Farid et al, 2019).

Benzimidazole derivatives (albendazole \& mebendazole), are the drugs used in the treatment of trichinellosis which have the characteristics of being broad-spectrum and highly efficient (Priotti et al, 2017). Nevertheless, they have a limited effect due to poor water solubility, low bioavailability and long-term application that may lead to drug resistance (Codina et al, 2015).

Curcumin is an important bioactive compound of Curcuma longa with medicinal value such as anti-inflammatory, anticancer, antioxidant, anti-atherosclerotic, antibacterial, antiviral, antifungal, and wound healing (Moghadamtousi et al, 2014; Hussein et al, 2021), as well as anti-protozoal activity as Trypanosoma brucei (Gressler et al, 2015), Giardia lamblia (Pérez-Arriaga et al, 2006), Leishmania donovani (Cheikh-Ali et al, 2015), and significant effect on experimental cerebral malaria (Waknine-Grinberg et al, 2010) and Schistosoma mansoni (Hussein et $a l$, 2017). Moreover, Cur had a beneficial role in animal models of liver toxicity, inflammation and cirrhosis (Lee et al, 2017) and multiple cardiovascular protective effects (Zeng et al, 2015). Also, Curcumin regulates TNF $\alpha$ production through downregulation of the pro-inflammatory transcription factors (Liu et al, 2013).

Curcumin has a modulatory impact on TGF- $\beta$ in different diseases; e.g., it protects liver cells against toxic agents by inhibition of TGF- $\beta$ (Ashrafizadeh et al, 2020). Most studies clarified the proinflammatory role of TGF- $\beta$ and its association with organ damage. This pro-inflammatory role was in favor of disease development and progression (Fionda et al, 2020). So, down-regulation of TGF- $\beta$ is important in suppressing inflammation-mediated disease development (Mazala et al, 2020). Also, Cur eliminated lipids in the cell membrane and reduced lipid peroxidation and serum cholesterol (Varatharajalu et al, 2016). Because of its antiapoptotic, antioxidative and anti-inflammatory abilities; Cur was widely used for preventing or treating a variety of diseases other than inflammation (Jiang et al, 2017).

Unfortunately, the therapeutic abilities of Cur are limited because of its poor solubility or stability in aqueous media and body fluids, high metabolic rate, fast clearance and low bioavailability (Tiwari et al, 2017). This was overcome by nanotization of Cur; which improved water solubility, bioavailability, 
plasma concentration, cellular permeability and enhances its activity against various microbial pathogens and parasites (Mokbel et al, 2020).

This study aimed to explore the anti-inflammatory, antioxidant, and anti-apoptotic effects of Cur and Cur-Nano in modulation of inflammatory and pathological changes in different organs in murine trichinellosis.

\section{Material and Methods}

Animals and Parasite: Forty laboratory bred Swiss Albino male mice (about 8 weeks old and $25 \pm 5$ grams) were obtained from the Laboratory Animal House in Theodore Bilharz Research Institute, Giza, Egypt. All mice were housed and fed according to the national guidelines and were approved by the Ethical Committee of the Faculty of Medicine, Menoufia University, Egypt.

Trichinella spiralis strain was kindly obtained from Medical Parasitology Department, Tanta University, Egypt. This strain was previously genotyped by the European Union Reference Laboratory for Parasites as it was maintained in the laboratory of Tanta University by consecutive passages through rats and mice.

Experimental design: Mice were randomly and equally divided into four groups (ten mice per group). GI: mice infected and treated with Cur, GII: mice infected and treated with Cur-Nano, GIII: infected non-treated mice (positive control) and GIV: non-infected non-treated mice (negative control). Mice were orally infected with $T$. spiralis larvae (200 larvae/ mouse)

Drugs: Curcumin from Curcuma longa (Sigma-Aldrich) dissolved in dimethylsulfoxide (DMSO, Sigma-Aldrich).

Curcumin nanoparticles were prepared by solvent-antisolvent precipitation (Devara et al, 2015). Briefly, Cur $(100 \mathrm{mg} / \mathrm{ml})$ was dissolved in ethanol (Vetec, 99.8\%), and then distilled water was used as antisolvent in the ratio of 1:10 and mixed well. The solution was sonicated for about $30 \mathrm{~min}$. After sonication, the mixture was stirred at $800 \mathrm{rpm}$ for about $20 \mathrm{~min}$ till the orange-colored pre- cipitate was obtained, and solution was kept at $25^{\circ} \mathrm{C}-40^{\circ} \mathrm{C}$ under a nitrogen atmosphere and high pressure into $0.1 \%-10 \%$. The particle size was analyzed by Horiba SZ-100 (Japan), particle size analyzer, and the final product consisted of Curcumin nanoparticles.

Dosage: Both Cur and Cur-Nano were used at a dose of $50 \mathrm{mg} / \mathrm{kg}$ for 5 days by oral route (Tiwari et al, 2017), who observed $90.85 \%$ parasite inhibition at this dose. The same dose was used to compare the potency of both drugs. The treatment was started on the $13^{\text {th }}$ dpi (Huang et al, 2020).

Mice scarifications and sample collection On the $30^{\text {th }}$ dpi, all mice were euthanized by cervical dislocation. Blood samples were withdrawn in plain tubes and were left at room temperature for 30 minutes, then centrifuged at $3000 \mathrm{rpm}$ for $15 \mathrm{~min}$ and serum was aliquoted. The serum was stored at -20 ${ }^{\circ} \mathrm{C}$ for subsequent biochemical measurement of ALT and AST and quantitative estimation of TNF $\alpha$, TGF $\beta$ and Trop. Lung, liver, brain (both cerebrum and hippocampus) and heart specimens were fixed in neutral buffered formalin ( $\mathrm{pH}$ 7.2) for further H\&E and immunohistochemical staining.

Counting T. spiralis larvae: To evaluate the effect of the treatment against migrating larvae, the mice were sacrificed on $30^{\text {th }}$ dpi. Mice carcasses were shredded and weighed, muscle encysted larvae were obtained by the pepsin digestion method and their number was calculated by microscopy. The worm reduction rate $=[$ (average number of parasites in the control group minus the average number in the treatment group) /average number of parasites in the control group] $\times 100 \%$.

Measurement of ALT \& AST: To assess hepatotoxicity, we measured the serum activity of ALT and AST using spectrophotometric diagnostic kits (Sigma-Aldrich) according to the manufacturer's recommendations (Lee et al, 2004).

Quantitative Estimation of TNF $\alpha$, TGF- $\beta, \&$ Trop by ELISA in mice sera were performed 
by validated manual microplate ELISA kits following manufacturer instructions. TNF $\alpha$ $\&$ TGF- $\beta$ Kits were purchased from Abcam, Catalogue No ab208348 \& ab119557 respectively. Troponin supplied by LifeSpan BioSciences, Catalogue No LS-F55154. According to standards' concentration and the corresponding optical density $(\mathrm{OD}=450 \mathrm{~nm})$ values, the standard curve linear regression equation was calculated out and the OD values of the sample were applied to the regression equation to calculate the corresponding sample's concentration.

Microscopic examination: Lung, liver, brain and heart specimens were fixed in neutral buffered formalin $(\mathrm{pH}$ 7.2). Sections were processed as usual at Pathology Department, National Liver Institute, Menoufia University before embedding in paraffin and mounted on glass slides. Sections $(5 \mu \mathrm{m}$ thick) were immersed in xylene and graded alcohol followed by H\&E staining (Bancroft and Gamble, 2008).

Immunohistochemical (IHC) studies: Immunoassay of streptavidin-biotin-amplified system was used. The primary antibodies used were anti-mouse caspase 3 diluted as 1:500 (Cat. \#9662), GFAP diluted as 1:100 (Cat.\#80788) obtained from Cell Signaling Technology, Massachusetts, USA, PPARs diluted as 1:200 (Cat.\#MBS2534561) obtained from MyBioSource, Southern California, San Diego (USA), arginase diluted as 1: 50 (Cat.\#2-AR007-12) obtained from Quartett, Berlin, Germany, $\mathrm{COX}_{2}$ diluted as 1:100 (Cat.\#187379) obtained from Invitrogen, California and granzyme b diluted as 1:200 (Cat.\#sc-8022) obtained from Santa Cruz Bio-technology, Texas, United States. After deparaffinization and rehydration of tissue, the antigen was retrieved using high $\mathrm{pH}$ EDTA solution followed by cooling at room temperature. The slides were incubated overnight at $4^{\circ} \mathrm{C}$ with primary antibodies. Secondary antibody using Ultravision detection system anti-polyvalent HRP/DAB, ready-to-use, Neomarker was applied, and staining was visualized using DAB chromogen substrate and Mayer's hematoxylin as a counterstain. Positive staining and negative controls were used in each run. Each antibody was assessed using histoscore (H-score) as follows: Strong intensity; $3 \mathrm{x} \%$, moderate intensity; $2 \mathrm{x} \%$, mild intensity; $1 \mathrm{x} \%$, negative staining; $0 \mathrm{x} \%$. A final score ranged from 0-300 (Kim et al, 2016).

Histopathological \& IHC analysis: 20 nonoverlapping represented high-power (400x) were examined for the number of inflammatory cells \& degenerative changes as follows:

Lung sections were assessed to detect bronchial epithelial proliferation, mucin secretion and goblet cells hyperplasia, inflammatory response, distribution, and type of infiltrating, (lymphocytes, plasma cell, eosinophils, macrophages and neutrophils (Gentilini et al, 2011). In addition, $\mathrm{COX}_{2}$ was assessed in the inflammatory infiltrate. Furthermore, the role of M2 macrophages in the inflammatory response against $T$. Spiralis was evaluated by assessing arginase expression (Kang et al, 2019), and the role of cytotoxic $\mathrm{T}$ cells and natural killer (NK) cells in host defense against $T$. spiralis by evaluation of granzyme $b$ expression.

Liver sections were assessed for severity, distribution and type of inflammatory response (lymphocyte, neutrophil and eosinophil infiltration), bile duct affection, and hepatocytes' degenerative changes. The expression of PPARs was assessed as a multirole in preventing the oxidative stress, metabolic abnormalities, inflammation and fibrosis induced by $T$. spiralis, and a possible association of PPARs and paraoxonases (PONs) was supported. PON is a marker regulating the metabolic changes induced by $T$. spiralis infection (Camps et al, 2012). $\mathrm{COX}_{2}$ and granzyme $\mathrm{b}$ expression was assessed using IHC.

Brain specimens were examined for inflammatory aggregates in meningeal layer, neuronal loss, neural cytoplasmic vacuolation and reactive gliosis. Lewy's body formation was also assessed. In addition, the 
hippocampus was examined for the thickness of the dentate gyrus pyramidal zone and neural apoptosis to predict the possibility of association of $T$. spiralis with epilepsy. Lewy's body formation was also assessed in the infected and treated groups because the association of $T$. spiralis and Parkinson's disease was postulated (Saad et al, 2018). The apoptosis of neurons was detected using anti-cleaved caspase 3IHC staining in parenchyma and hippocampus. Reactive astrocytes and gliosis were highlighted by GFAP.

Heart tissue was assessed for degenerative changes in cardiomyocytes in the form of hyper-eosinophilic fibers, fatty infiltration, interstitial fibrosis, fibrosis and necrosis. Grading of myocardial injury was made as follows: grade 1; intact and homogenous cardiomyocytes, grade 2 ; focal myocardial necrosis, grade 3; focal myocardial necrosis associated with edema and inflammation and grade 4; extensive or multifocal myocardial necrosis and inflammation (Boarescu et al, 2019). Masson trichrome stain was used to assess fibrosis. To assess necrosis and apoptosis of cardiomyocytes; an anti-cleaved caspase 3 antibody was used in IHC.

Statistical analysis: Data were tabulated as mean, Median, and range and analyzed by a statistical package for the Social Science Software (SPSS) software (version 17.0 on an IBM compatible computer; SPSS Inc., Chicago, Illinois, USA). Kruskal-Wallis test was used for comparison between three or more groups having not normally distributed quantitative data. While, Mann Whitney test was used when 2 sets of quantitative data were not normally distributed. Spearman's correlation was used to study correlation between two quantitative variables. P-value was used to test significance in experimental animals among the different groups. P-value was set at $0.05, \mathrm{P}>0.05$ non-significant, $\mathrm{P}$ $<0.05$ significant and $\mathrm{P}<0.001$ highly significant (Peat and Barton, 2005).

\section{Results}

Number of $T$. spiralis larvae in treated GI $\&$ GII was significantly reduced $(\mathrm{P}<0.001)$ compared with that in parasite control, GIII. Larval reduction rate of Cur and Cur-Nano was $62.19 \& 41.06$ respectively.

There was a highly significant $(\mathrm{P}<0.001)$ decrease in serum levels of AST \& ALT in GI \& GII compared to positive control (GIII), but without significant $(\mathrm{P} 1=0.03)$ reduction in the mean levels of AST \& ALT between mice treated by Cur and Cur-Nano.

Mean levels of TNF $\alpha$, TGF- $\beta, \&$ Trop in positive control were $179.45,505.9, \& 12.65$ respectively, with a significant increase as compared to negative control. Mean levels of TNF $\alpha$, TGF- $\beta$ \& Trop in Cur and CurNano treated groups were $100.3,167.7 \&$ $4.3 \& 130.3,319.4 \& 6.95$ respectively. There was a significant reduction in mean levels of TNF $\alpha$, TGF- $\beta$, \& Trop in both treated mice as compared to positive control.

Significant lung damage was observed in positive control in form of substantial bronchial epithelial proliferation, mucin secretion and goblet cell hyperplasia. Also, a significant inflammatory response is widely distributed throughout lung tissue in form of BALT, perivascular, parenchymal and pleural lymphoid tissue. Localization of the inflammatory infiltrates differed with a prominent perivascular and peri-bronchial eosinophilic infiltrate, while macrophage and lymphocytes dominated the parenchymal and pleural regions. There was a significant improvement $(\mathrm{P}<0.001)$ of bronchial epithelial proliferation in both treated groups when compared to infected group.

The burden of eosinophils significantly declined in both treated groups compared to infected group $(\mathrm{P}<0.001)$; median eosinophils count was 61.5 in infected group vs. 18 \& 9 eosinophils/10 high power field (HPF) in Cur and Cur-Nano treated groups, respectively. There was a significant improvement of inflammatory injury in GII compared to GI $(\mathrm{P}<0.001)$, and improvement of alveolar $\&$ pleural inflammation $(\mathrm{P}<0.001)$ in GI \& GII compared to GIII.

There was a significant over-expression of $\mathrm{COX}_{2}$ in GIII (median $\mathrm{COX}_{2}$ H. score 82.5); 
compared to both treated groups $(\mathrm{P}<0.001)$. The expression of $\mathrm{COX}_{2}$ was significantly low in the Cur-Nano treated group compared to the Cur treated group, with median $\mathrm{H}$ score of $20 \& 25$ respectively $(\mathrm{P}<0.001)$.

The significant overexpression $(\mathrm{P}<0.001)$ of macrophage arginase activity was in GIII with median $\mathrm{H}$. score 125 compared to GI \& GII with median H. score of $50 \& 35$, respectively. A significant low expression of granzyme b secreting neutronphils $(\mathrm{P}<0.001)$ was in Cur \& Cur-Nano treated groups compared to infected one with median $\mathrm{H}$. score of 65 in GIII vs. $45 \& 5$ in GI \& GII, respectively. There was a positive correlation between both sera of TGF $\alpha$, TNF- $\beta \& \mathrm{COX}_{2}$ expression in lung tissue $(\mathrm{P}<0.001)$.

In positive control group; liver tissue showed bile duct injury and proliferation compared to both treated groups. Eosinophilbased portal tract inflammation was significantly marked in GIII compared to GI \& GII with median of eosinophils of 57.5 in GIII compared to $22 \& 16 / 10 \mathrm{HPF}$ in GI \& GII respectively $(\mathrm{P}<0.001)$. Perivenular inflammation was significantly in GIII compared to GI \& GII $(\mathrm{P}<0.001)$.

There was a significant overexpression of $\mathrm{COX}_{2}$ in the inflammatory infiltrate in infected group with median $\mathrm{H}$. score of 72.5 compared to both treated groups with median $\mathrm{COX}_{2} \mathrm{H}$. score of $47.5 \& 5$ in Cur treated \& Cur-Nano treated groups, respectively $(\mathrm{P}<0.001)$. A significantly low expression of PPAR was in GIII with median $\mathrm{H}$ score of 2.5 compared to GI \& GII $(\mathrm{P}<0.001)$. PPAR was significantly overexpressed in Cur-Nano treated group with median $\mathrm{H}$ score of 60 compared to Cur treated group with median $\mathrm{H}$ score of $20(\mathrm{P}<0.001)$.

Protein expression of granzyme $\mathrm{b}$ as a surrogate marker of cell-mediated cytotoxicity against trichinellosis was high in infected group with median $\mathrm{H}$ score of 90 compared to both treated groups $(\mathrm{P}<0.001)$. Expression was subsequently significantly decreased in the Cur-Nano treated group with median $\mathrm{H}$ score of 7.5 compared to Cur treated group with median $\mathrm{H}$ score of $45(\mathrm{P}<0.001)$.

There was a positive correlation between serum TGF $\alpha$, TNF- $\beta$ and $\mathrm{COX}_{2}$ expression in liver tissue $(\mathrm{P}<0.001)$. The positive correlation between serum ALT and granzyme $b$ hepatic expression $(\mathrm{r}=0.911, \mathrm{P}<0.001)$ was found. Also, there was a positive correlation between serum ALT and hepatic $\mathrm{COX}_{2}$ expression $(\mathrm{r}=0.58, \mathrm{P}=0.07)$. There was an inverse correlation between serum ALT \& PPAR expression $(\mathrm{r}=-0.922, \mathrm{P}<0.001)$.

Brain specimens of infected group showed significant thinning of the dentate gyrus' pyramidal zone due to neural loss in hippocampus compared to treated groups $(\mathrm{P}=0.001)$. There was a thickening of the meningeal layer by prominent lymphocytic inflammation in GIII compared to GI \& GII. Inflammation was significantly declined in Cur treated group to complete absent in Cur-Nano treated group $(\mathrm{P}=0.02)$. GIII showed degenerative changes in form of neural cytoplasmic vacuolization, smudge hyperchromatic nuclei, prominent neural loss and reactive gliosis. Degenerative changes were improved in GI \& GII. Lewy's bodies were counted in GIII compared to GI \& GII (median Lewy's bodies $5 / \mathrm{HPF}$ in GIII vs. 3 \&1/HPF in GI \& GII, respectively).

The highest expression of GFAP was in infected group with median $\mathrm{H}$. score of 75 compared to both treated groups $(\mathrm{P}<0.001)$. GFAP was low expressed significantly in Cur-Nano treated group with median $\mathrm{H}$. score of 22.5 compared to Cur treated group with median $\mathrm{H}$. score of $50(\mathrm{P}<0.001)$. The neural apoptosis showed that Caspase 3 expression was marked in GIII (caspase $3 \mathrm{H}$. score 107) compared to GI \& GII $(\mathrm{P}<0.001)$. Low expression of caspase 3 was significant in Cur-Nano treated group with median $\mathrm{H}$. score of 5 compared to Cur treated ones with median $\mathrm{H}$ score of $30(\mathrm{P}<0.001)$.

Histopathological changes of heart in infected group were in the form of fibrotic changes of cardiomyocytes rather than inflammatory injury, which was absent in both treated groups. Grade of injury varied from se- 
vere damage in form of multifocal necrosis, fat infiltration and fibrotic changes in GIII compared to GI \& GII. Cardiomyocytes of infected group showed a high apoptotic activity highlighted by caspase 3 ICH study with median $\mathrm{H}$. score of 152.5 compared to treated groups $(\mathrm{P}<0.001)$. Apoptotic activity was significantly low in Cur-Nano treated group with median H. score of 15 compared to Cur treated ones with median $\mathrm{H}$. score of $65(\mathrm{P}<0.001)$. A positive correlation was between serum Trop level \& expression of caspase 3 in heart samples $(\mathrm{r}=0.73, \mathrm{P}=0.01$, $\mathrm{r}=0.74$ and $\mathrm{P}=0.01$, respectively).

Details were given in tables $(1,2, \& 3)$ and figures $(1,2,3, \& 4)$.

Table 1: Comparison between all infected groups regarding larva count and reduction rate

\begin{tabular}{|l|l|l|l|l|l|}
\hline Studied variable & GI $(\mathrm{N}=10)$ & GII $(\mathrm{N}=10)$ & GIII $(\mathrm{N}=10)$ & p- value & Post hoc \\
\hline Larva count & & & & $*<0.00$ & \\
Mean & 29800.0 & 19080.0 & 50660.0 & 1 & $\mathrm{P} 1=<0.001$ \\
Median & 29900.0 & 18900.0 & 50900.0 & & $\mathrm{P} 2=<0.001$ \\
Min-max & $28200.0-31000.0$ & $18000.0-20400.00$ & $48600.0-52800.0$ & & $\mathrm{P} 3=<0.001$ \\
\hline Reduction (\%) & & & & & \\
Mean & 41.15 & 62.32 & --- & $* *<0.0$ & --- \\
Median & 41.06 & 62.19 & & 01 & \\
Min-max & $39.18-\quad 43.60$ & $59.20-\quad 65.52$ & & & \\
\hline
\end{tabular}

P- value of Kruskal-Wallis test, **P- value of Mann Whitney test, P1=+ve control\& Infected TTT by Cur, P2=+ve control\& Infected ttt by Cur-Nano. P3= Infected TTT by Cur \& Infected TTT by Cur-Nano

Table 2: Serum biochemical markers (ALT \& AST) comparison between all groups:

\begin{tabular}{|c|c|c|c|c|c|c|}
\hline Studied variable & GI $(\mathrm{N}=10)$ & GII $(\mathrm{N}=10)$ & GIII $(\mathrm{N}=10)$ & GIV $(\mathrm{N}=10)$ & *p-value & Post hoc \\
\hline $\begin{array}{l}\text { AST IU/L } \\
\text { Mean } \\
\text { Median } \\
\text { Min-max }\end{array}$ & $\begin{array}{l}30.84 \\
30.90 \\
30.20-31.30\end{array}$ & $\begin{array}{l}29.15 \\
29.20 \\
28.50-29.80\end{array}$ & $\begin{array}{l}65.0 \\
65.0 \\
61.0-69.0\end{array}$ & $\begin{array}{l}24.3 \\
24.5 \\
21.0-28.0\end{array}$ & $<0.001$ & $\begin{array}{l}\mathrm{P} 1=0.03 \\
\mathrm{P} 2=<0.001 \\
\mathrm{P} 3=<0.001 \\
\mathrm{P} 4=<0.001 \\
\mathrm{P} 5=<0.001 \\
\mathrm{P} 6=<0.001\end{array}$ \\
\hline $\begin{array}{l}\text { ALT IU/L } \\
\text { Mean } \\
\text { Median } \\
\text { Min-max }\end{array}$ & $\begin{array}{l}41.83 \\
41.15 \\
39.5-49.7\end{array}$ & $\begin{array}{l}38.56 \\
38.65 \\
37.4-39.7\end{array}$ & $\begin{array}{l}85.1 \\
87.0 \\
80.0-89.0\end{array}$ & $\begin{array}{l}35.9 \\
35.8 \\
35.1-36.5\end{array}$ & $<0.001$ & $\begin{array}{l}\mathrm{P} 1=0.03 \\
\mathrm{P} 2=<0.001 \\
\mathrm{P} 3=0.001 \\
\mathrm{P} 4=<0.001 \\
\mathrm{P} 5=<0.001 \\
\mathrm{P} 6=<0.001\end{array}$ \\
\hline
\end{tabular}

NB: *P- value of Kruskal-Wallis test

Table 3: Correlation between serology and IHC in lung, liver and heart tissues

\begin{tabular}{|c|c|c|}
\hline \multicolumn{2}{|c|}{ Correlation between serum TGF $\beta$, TNF $\alpha$, and $\mathrm{COX}_{2}$ expression in lung and liver tissues } \\
\hline & $\mathrm{COX}_{2}$ LIVER & $\mathrm{COX}{ }_{2}$ LUNG \\
\hline TGF $\beta$ & $\mathrm{r}=0.93,(\mathrm{P}=<0.001)$ & $\mathrm{r}=072,(\mathrm{P}=<0.001)$ \\
$\mathrm{TNF} \alpha$ & $\mathrm{r}=0.87,(\mathrm{P}=<0.001)$ & $\mathrm{P}=<0.001)$ \\
\hline Correlation between serum ALT \& IHC expression of granzyme $\mathrm{b}, \mathrm{COX}_{2}$, and PPAR in liver tissue \\
\hline \multicolumn{2}{|c|}{$\mathrm{ALT}$} \\
\hline Granzyme b & $\mathrm{r}=0.91,(\mathrm{P}=<0.001)$ \\
\hline COX $_{2}$ & $\mathrm{r}=0.58,(\mathrm{P}=0.07)$ \\
\hline PPAR & $\mathrm{r}=-0.92,(\mathrm{P}=<0.001)$ \\
\hline \multicolumn{2}{|c|}{ Correlation between serum Trop and IHC expression of Caspase3 in heart tissue } \\
\hline \multicolumn{2}{|c|}{ Trop } \\
\hline \multicolumn{2}{|c|}{$\mathrm{r}=0.74,(\mathrm{P}=0.01)$} \\
\hline
\end{tabular}

\section{Discussion}

In the present study, there was anti-Trichinella effect by Cur and Cur-Nano. Number of larvae in both treated groups was significantly reduced compared to control group. The worm reduction rates of Cur and CurNano were $40.06 \& 62.19$, respectively. This agreed with Mokbel et al. (2020). Magalha- es et al (2009) reported that Cur treatment modulated humoral and cellular immune responses of Schistosoma mansoni-infected mice and led to a significant reduction of parasite burden and liver pathology. Tiwari et al. (2017) found that Nano-formulation of Cur alone or in combination with miltefosine caused significant in vitro \& in vivo leishmani- 
cidal activity, increased toxic reactive oxygen/nitrogen metabolites, and enhanced lymphocyte proliferation and phagocytosis.

In the present study, biochemical results showed a significant increase in levels of AST \& ALT in the infected control group as compared with the non-infected group. This change is due to hepatic damage caused by migrating NBL (Gamble et al, 1997). Also, there was an improvement in biochemical parameters in both treated groups, which agreed with Nada et al (2018). There was a remarkable improvement of the biochemical parameters in GII that received Cur-Nano compared to GI received Cur. This was attributed to the increased solubility, bioavailability and efficiency of nanoparticles. Dende et al. (2017) reported the same results in experimental cerebral malaria.

The present results showed that Cur reduced TGF- $\beta, \mathrm{TNF} \alpha, \mathrm{COX}_{2}, \& \mathrm{NF}-\kappa \mathrm{B}$, the important inflammation primary mediators. This proved the Cur protective/meliorative effect on murine trichinellosis in migratory phase in lung, liver, brain and heart. The results also agreed with the concept that sera TGF- $\beta$ $\& \mathrm{TNF} \alpha$ were a useful parameter to evaluate therapeutic effects of Cur and Cur-Nano in murine trichinellosis. Besides, both Cur \& Cur-Nano induced a significant immunological alteration in infected mice. This agreed with Hernández et al. (2018), Ali et al. (2019); Asadi et al. (2020). A high level of TGF- $\beta$ was proved to help in the downregulation of the parenteral phase inflammation and facilitated tissue invasion by NBL. TGF- $\beta 1$ receptors proved to be upregulated in some organs not commonly invaded by $T$. spiralis (Toms and Powrie, 2001). Bliss et al, (2003) also recorded an increase in the larval capability to invade liver in the presence of a high TGF- $\beta$ level. But, in the present study, despite high TGF- $\beta$ level detected in infected mice, there was no $T$. spiralis larvae organ invasion.

In the present study, lung tissues were significant damaged in the infected non-treated group in the form of substantial bronchial epithelial proliferation, mucin secretion and goblet cell hyperplasia. Also, there was a significant inflammatory response widely distributed via lung tissue in the form of bronchial associated lymphoid tissue, perivascular, parenchymal and pleural. This agreed with Gentilini et al. (2011). Trichinellosis rapidly induced lung inflammatory response to helminthocytotoxic activity. Ierna et al. (2009) found that inflammatory process during trichinellosis in the lung resulted from a signal originated in the gut due to larval penetration into its epithelium with development of an inflammatory process with the rejection of the adult worms from such mucosa.

In the present study, there was significant improvement of bronchial epithelial proliferation and lung injury in both treated groups compared to infected ones. This agreed with Huang et al. (2019) who found that Cur reduced the lung damage (induced by airborne particles), and increased heme oxygenase expression in lung tissue, the endogenous active enzyme widely distributed in damaged organs and played a role in protecting tissues and organs by anti-oxidation, anti-inflammation and anti-apoptosis. Also, Almatroodi et al. (2020) reported that Cur had a protective role against benzopyrene-induced lung damage, where the Cur attenuated lung inflammation and decreased inflammatory mediators as $\mathrm{TNF} \alpha$, oxidative stress and apoptosis in epithelial cells by improving cell proliferation and antioxidants level.

In the present study, there was significant overexpression of $\mathrm{COX}_{2}$ in infected group compared to both treated ones. This agreed with Shaikh and Bhandary (2020) who reported that Cur blocked expression of $\mathrm{COX}_{2}$, the critical role in the emergence of pulmonary fibrosis, indicating the potentials of Cur as an adjuvant anti-inflammatory therapeutic agent for treating lung injury. Besides, there was a positive correlation between sera of TGF $\alpha$, TNF- $\beta$, \& lung $\mathrm{COX}_{2}$ expression. This agreed with Lee et al. (2005) who reported that Cur inhibited IFN $\alpha$-induced $\mathrm{COX}_{2}$ expression in lung A549 cells. In addition, 
there was a significant overexpression of macrophage arginase activity. Highest TGF$\beta$ level was recorded in infected group compared to Cur and Cur-Nano treated ones. This agreed with Falduto et al. (2015) who found the immunomodulatory properties exerted by NBL during passage via lung tissue. Also, there was a significant low expression of granzyme b secreting neutrophils in both treated groups compared to the infected one. This agreed with Boussoffara et al. (2018) who reported the presence of high levels of granzyme $b$ in endemic foci of Leishmania major with previous contact with the parasite compared to the healthy ones. Granzyme b produced stimulation with Leishmania-antigens in CD4+ $\mathrm{T}$ cells; including $\mathrm{T}$ regulatory cells; as a good marker of immunity and cytotoxicity in cutaneous leishmaniasis.

In the present study, Cur \& Cur-Nano caused hepatoprotective effect against ischemia/ reperfusion promoted liver injury. This went with Farzaei et al. (2018) who found that Cur reduced some liver injuries as inflammatory responses and oxidative stress during reperfusion-induced hepatic injury. Besides, Cur treated damages of opisthorchiasis infected hamsters by reduced inflammatory cell aggregation surrounding hepatic bile ducts and reduced cholangiocarcinoma risk (Boonjaraspinyo et al, 2009).

TGF- $\beta$ is one of the signaling pathways downregulated by Cur in alleviation of liver fibrosis (Abo-Zaid et al, 2020). Chen and $\mathrm{Fu}$ (2018) reported that Cur supplementation decreased paraquatmediated liver injury by TGF- $\beta$ downregulation signaling pathway, and inhibited TGF- $\beta$, and protected liver ce1ls against toxic agents, and incorporation of Cur into polymeric nanoparticles significantly enhances its bioavailability and therapeutic impacts, leading to amelioration of liver injury (El-Naggar et al, 2019).

In this study, marked improvement of hepatic inflammation and decreased expression of $\mathrm{COX}_{2}$ occurred in both treated groups. This agreed with Nagajyothi et al. (2012) who found a significant reduction in macro- phage infiltration and inflammation in heart and liver of $T$. cruzi-infected mice after Cur treatment with significant decrease in $\mathrm{COX}_{-2}$ mRNA levels and infection-induced inflammation by anti-inflammatory property.

In the present study, there was a positive correlation between sera TGF $\alpha$, TNF- $\beta$ \& liver $\mathrm{COX}_{2}$ expression. This agreed with Domitrović et al (2011). The proinflammatory effects of TNF $\alpha$ were primarily due to its ability to activate NF- $\mathrm{KB}$, the important pathophysiology of inflammatory response (Dobrovolskaia and Kozlov, 2005) and led to the expression of inflammatory genes such as $\mathrm{COX}_{2}$, inflammatory cytokines, chemokines and induced nitric oxide synthase (Shishodia, 2013). In the present study, there was a positive correlation between sera ALT \& hepatic $\mathrm{COX}_{2}$ expression, which agreed with Hwang et al. (2011) and Neamatallah et al (2018). Also, there was a significantly low expression of PPAR in the infected group compared to treated ones. This agreed with Farid et al. (2017). These changes decreased hepatic paraoxonase-1 (PON1) responsible for metabolism of toxic oxidized lipids (Aviram et al, 2000). Besides, there was significant overexpression of PPAR in liver tissue in both treated groups. PPAR possessed a potent anti-inflammatory efficacy (Ricote et $a l, 1999)$ and suppressed TGF- $\beta 1 / \mathrm{Smad} 3$ signaling (Lin et al, 2011).

In the present study, expression of granzyme $b$ as marker of cell-mediated cytotoxicity against trichinellosis was high in infected mice compared to treated ones. This agreed with Ahn et al. (2016). Also, there was a positive correlation between serum ALT \& hepatic expression of granzyme $b$, which agreed with Stout-Delgado et al (2007). There was an inverse correlation between sera ALT \& PPAR expression. This agreed with Mahmoud et al. (2019) Granzyme b released by activated Treg cells induced apoptosis of naive B cells (Shevach et al, 2006). Therefore, T. spiralis is assumed to activate Treg cells leading to suppression of the host Th2 anti-Trichinella immune response. 
In the present study, there was effect of $T$. spiralis infection in brain tissue. This agreed with Saad et al. (2018) who found cortical atrophy with neuronal loss, increased apoptotic neurons, cytoplasmic vacuolation and scattered Lewy's bodies in T. spiralis infected mice.

In the current study, there was high mean level of TGF- $\beta$ in the infected control group. Piera-Velazquez et al (2016) reported that TGF- $\beta$ has a potent profibrogenic growth factor involved in the regulation of the brain's response to inflammation and injury. The increased levels of TGF- $\beta$ in GIII were convenient with the deposition of scar tissue and gliosis in specimens. This agreed with Beshay et al (2020). The assessment of reactive astrocytes and density of gliosis was performed using GFAP which was significantly low expressed in both treated groups. This agreed with Bondan et al (2017) who found that Cur reduced glial scar development and decreased GFAP expression. The glial scar acted as a physical barrier between the injured and normal cells, paved the way to restore an intact blood-brain barrier (Rohl et al, 2007). Daverey et al (2016) found that Cur has bifunctional antioxidant properties; by removing reactive oxygen species and simultaneously induction of antioxidant response. Curcumin led to the induction of cytoprotective enzymes, the reversion of mitochondrial dysfunctions in astrocytes and the inhibition of mitochondria-dependent and -independent apoptosis caused by oxidative damage.

In the present study, there was marked improvement of degenerative changes and low expression of caspase 3 in GI \& GII compared to GIII. Zaki et al. (2020) reported improvement of apoptotic changes with the Cur as compared to control group. Caspase3 is the most abundant of the recognized caspases in the brain (Kuida et al, 1999). The vital structural and functional proteins of cell led to apoptosis (Li et al, 2015). Olson (1999) found that in cerebral trichinellosis lesions were limited by neurons apoptosis, non-purulent meningitis and cellular infil- tration. The tight junctions of blood-brain barrier prevented larval passage from circulation (Ginhoux et al, 2013). This may explain why no larvae or granuloma were detected in brain sections of the present infected group.

In the present study, there was marked improvement of the degenerative changes in cardiac muscles in both treated groups, with best improvement in Cur-Nano treated group compared to Cur-treated one. This agreed with Boarescu et al. (2019) who found that all doses of cur and Cur-Nano offered a cardioprotective effect by preventing creatine kinase-MB leakage from cardiomyocytes, with the best result for Cur-Nano. Thus, improving the bioactivity of Cur by nanotechnology may help limit cardiac injury after myocardial infarction. The beneficial effects of Cur in heart diseases proved the role of Cur in regulating cardiac homeostasis, prevented and reversed cardiac hypertrophy and failure in animal models (Ghosh et al, 2010).

In the present study, mean value of Trop decreased in both treated groups compared to control positive one. This agreed with $\mathrm{Na}$ har and Akhter (2018) who found that the cardioprotective effect of Cur in isoproterenol-induced myocardial infarction in Wistar albino rats, as it decreased Trop level.

In the present study, there was lowest mean value in Cur-Nano treated group than Cur-treated one. This agreed with Boarescu et al (2019). Also, Cur protected reperfusion injury-induced cardiac dysfunction and myocardial injury in rats, and pretreatment improved the myocardial injury by decreasing serum levels creatine kinase-MB level \& Trop I (Chen et al, 2013).

In the present study, cardiomyocytes of the infected group showed a high apoptotic activity manifested by caspase 3 overexpression compared to treated groups. Apoptotic activity was significantly low in Cur-Nano treated group compared to Cur-treated one. Besides, there was a positive correlation between serum Trop \& cardiac expression of caspase 3. This agreed with Yeh et al (2005) 
and Liu et al (2017). Liu et al (2019) found that Cur effectively reduced myocardial injury, inhibited myocardial apoptosis and improved cardiac functions.

\section{Conclusion}

Curcumin is a plant with a remarkable nontoxic bioactive agent with medical properties. It improved the pathological changes and inflammatory induced in T. spiralis infected mice. Cur therapeutic effects were mediated in part by anti-inflammatory, antioxidant \& anti-apoptotic activities. Cur-Nano gave more significant effects. Thus, Cur-Nano activity versus Cur-based interventions in amelioration of pathogenesis and inflammation was in trichinellosis different organs.

Conflicts of interest: The authors neither had conflicts of interest nor received fund.

Authors' contributions: All authors equally contributed and approved the final article.

\section{References}

Abo-Zaid, MA, Shaheen, ES, Ismail, AH, 2020: Immunomodulatory effect of curcumin on hepatic cirrhosis in experimental rats. J. Food. Biochem. 44, 6:e13219.

Ahn, JB, Kang, SA, Kim, DH, Yu, HS, 2016: Activation and recruitment of regulatory $T$ cells via chemokine receptor activation in Trichinella spiralis-infected mice. Korean J. Parasitol. 54, 2: 163-71.

Ali, AH, Sudi, S, Basir, R, Embi, N, Sidek, H M, 2017: The Antimalarial Effect of Curcumin Is Mediated by the Inhibition of Glycogen Synthase Kinase-3 $\beta$. J. Med. Food. 20, 2:152-61.

Almatroodi, SA, Alrumaihi, F, Alsahli, MA, Alhommrani, MF, Khan, A, et al, 2020: Curcumin, an active constituent of turmeric spice: Implication in the prevention of lung injury induced by Benzo (a) Pyrene (BaP) in rats. Molecules 25, 3:724-6.

Asadi, A, Nezhad, DY, Javazm, AR, Khanicheragh, P, Mashouri, L, et al, 2020: In vitro effects of curcumin on transforming growth factor- $\beta$-mediated non-Smad signaling pathway, oxidative stress, and pro-inflammatory cytokines production with human vascular smooth muscle cells. Iran. J. Allergy. Asthma Immunol.19, 1: 84-93.

Ashrafizadeh, M, Zarrabi, A, Hushmandi, K, Zarrin, V, Moghadam, ER, et al, 2020: Towa- rd regulatory effects of curcumin on transforming growth factor-beta across different diseases: A review. Front. Pharmacol. 11:585413.

Aviram, M, Hardak, E, Vaya, J, Mahmood, S, Milo, S, et al, 2000: Human serum paraoxonases (PON1) Q \& R selectively decrease lipid peroxides in human coronary and carotid atherosc-1erotic lesions: PON1 esterase and peroxidase-like activities. Circulation 101, 21:2510-7.

Bancroft, J, Gamble, A, 2008: Theory and Practice of Histological Techniques. $6^{\text {th }}$ Ed. New York, London: Churchill Livingstone.

Beshay, EVN, El-Refai, SA, Sadek, GS, Elbadry, AA, Shalan, FH, et al, 2020: Mesenchymal stem cells combined with albendazole as a novel therapeutic approach for experimental neurotoxocariasis. Parasitology147, 7:799-809.

Bliss, SK, Alcaraz, A, Appleton, JA, 2003: IL10 prevents liver necrosis during murine infection with Trichinella spiralis. J. Immunol. 171, 6: 3142-7.

Boarescu, PM, Chirilă, I, Bulboacă, AE, Bocșan, IC, Pop, RM, et al, 2019: Effects of curcumin nanoparticles in isoproterenol-induced myocardial infarction. Oxid. Med. Cell. Longev. 78: 47142.

Bondan, E, Cardoso, C, Martins, MDF, 2017: Curcumin decreases astrocytic reaction after gliotoxic injury in the rat brainstem. Arq. Neuropsiquiatr. 75, 8:546-52.

Boonjaraspinyo, S, Boonmars, T, Aromdee, C, Srisawangwong, T, Kaewsamut, B, et al, 2009: Turmeric reduces inflammatory cells in hamster opisthorchiasis. Parasitol. Res. 105, 5: 1459-63.

Boussoffara, T, Chelif, S, Ahmed, MB, Mokni, $M$, Salah, AB, et al, 2018: Immunity against Leishmania major Infection: Parasite-specific granzyme $\mathrm{b}$ induction as a correlate of protection. Front. Cell Infect. Microbiol. 8:397-9.

Bruschi, F, Solfanelli, S, Binaghi, RA, 1992: Trichinella spiralis: modifications of the cuticle of the newborn larva during passage through the lung. Exp. Parasitol. 75:1-9

Bruschi, F, Gómez-Morales, MA, Hill, DE, 2019: International commission on trichinellosis: Recommendations on the use of serological tests for the detection of Trichinella infection in animals \& humans. F. W. Parasitol. 14: e00032. Camps, J, García-Heredia, A, Rull, A, Alonso-Villaverde, C, Aragonès, G, et al, 2012: PPARs in regulation of paraoxonases: Control of 
oxidative stress and inflammation pathways. PPAR, Res. 2012: 616371.

Cheikh-Ali, Z, Caron, J, Cojean, S, Bories, C, Couvreur, P, et al, 2015: Squalenoylcurcumin; nanoassemblies as water-dispersible drug candidates with antileishmanial activity. Chem. Med. Chem. 10, 2:411-8.

Chen, H, and Fu, X, 2018: Dynamics study on the role of curcumin on TGF- $\beta 1$ expression and pathological changes in acute paraquat poisoned rats. Exp. Ther. Med. 16, 5:3841-6.

Chen, TH, Yang, YC, Wang, JC, Wang, JJ, 2013: Curcumin treatment protects against renal ischemia and reperfusion injury induced cardiac dysfunction and myocardial injury. Transplant. Proc. 45, 10:3546-9

Codina, AV, Garcia, A, Leonardi, D, Vasconi, MD, Di Masso, RJ, et al, 2015: Efficacy of albendazole: $\beta$-cyclodextrin citrate in the parenteral stage of Trichinella spiralis infection. Int. J. Biol. Macromol., 77: 203-6.

Daverey, A, Agrawal, SK, 2016: Curcumin alleviates oxidative stress and mitochondrial dysfunction in astrocytes. Neuroscience333:92-103.

Dende, C, Meena, J, Nagarajan, P, Nagaraj, VA, Panda, AK, et al, 2017: Nanocurcumin is superior to native curcumin in preventing degenerative changes in experimental cerebral malaria. Sci. Rep. 7:10062-8.

Despommier, DD, 1993: Trichinella spiralis and the concept of niche. J. Parasitol. 79:472-82

Devara, RK, Mohammad, HUR, Rambabu, B, Aukunuru, J, Habibuddin, M, 2015: Preparation, optimization and evaluation of intravenous curcumin nanosuspension intended to treat li$=$ ver fibrosis. Turk. J. Pharm. Sci. 12, 2:207-20.

Dobrovolskaia, MA, Serguei V Kozlov, SV, 2005: Inflammation and cancer: When NF-kappaB amalgamates the perilous partnership. Curr. Canc. Drug Targets 5, 5:325-44.

Domitrović, R, Jakovac, H, Blagojević, G, 2011: Hepatoprotective activity of berberine is mediated by inhibition of TNF- $\alpha, \mathrm{COX}_{-2}$, and iNOS expression in CCl4-intoxicated mice. Toxicology 280, 1/2:33-43.

El-Naggar, ME, Al-Joufi, F, Anwar, M, Attia, MF, El-Bana, MA, 2019: Curcumin-loaded PLA-PEG copolymer nanoparticles for treatment of liver inflammation in streptozotocin-induced diabetic rats. Colloids Surf. B. Biointerfaces 177:389-98.

Falduto, GH,Vila, CC, Saracino, MP, Calcagno, MA, Venturiello, MS, 2015: Trichinella spiralis: Killing of newborn larvae by lung cells. Parasitol. Res. 114:679-85

Farid, AS, Fath, EM, Mido, S, Nonaka, N, Horii, Y, 2017: Paraoxonase-1 activity is related to Trichinella spiralis induced hepatitis in rats. Eur. J. Clin. Invest. 47, 3:250-61.

Farid, AS, Fath, EM, Mido, S, Nonaka, N, Horii, Y, 2019: Hepatoprotective immune response during Trichinella spiralis infection in mice. J. Vet. Med. Sci. 81, 2:169-76.

Farzaei, MH, Zobeiri, M, Parvizi, F, El-Senduny, FF, Marmouzi, I, et al, 2018: Curcumin in liver diseases: A systematic review of the cellular mechanisms of oxidative stress and clinical perspective. Nutrients 10, 7:855-9.

Fionda, C, Stabile, H, Cerboni, C, Soriani, A, Gismondi, A, et al, 2020: Hitting more birds with a stone: Impact of TGF-beta on ILC activity in cancer. J. Clin. Med. 9, 1:143-6.

Gamble, HR, Wisnewski, N, Wasson, DL, 1997: Diagnosis of trichinellosis in swine by enzyme immunoassay, using a synthetic glycan antigen. Am. J. Vet. Res. 58, 12:1417-21.

Gentilini, MV, Nuñez, GG, Roux, ME, Venturiello, SM, 2011: Trichinella spiralis infection rapidly induces lung inflammatory response: The lung as the site of helminthocytotoxic activity. Immunobiology 216, 9:1054-63.

Ghosh, SS, Salloum, FN, Abbate, A, Krieg, R, Sica, et al, 2010: Curcumin prevents cardiac remodeling secondary to chronic renal failure through deactivation of hypertrophic signaling in rats. Am. J. Physiol. Heart. Circ. Physiol. 2994:H975-84.

Ginhoux, F, Lim, S, Low, D, Huber, T, Hoeffel, G, 2013: Origin and differentiation of microglia. Front. Cell. Neurosci. 7, 45:6159-69.

Gressler, LT, Oliveira, CB, Coradini, K, Rosa, L, Dalla, Grando, TH, et al, 2015: Trypanocidal activity of free and nanoencapsulated curcumin on Trypanosoma evansi. Parasitol. Camb. 142, 3:439-48.

Hernández, M, Wicz, S, Santamaría, MH, Corral, RS, 2018: Curcumin exerts anti-infla-mmatory and vasoprotective effects through amelioration of NFAT-dependent endothelin-1 production in mice with acute Chagas cardiomyopathy. Mem. Inst. Oswaldo Cruz.113, 9:e180171. Huang, H, Yao, J, Liu, K, Yang, W, Wang, G, et al, 2020: Sanguinarine has anthelmintic activity against the enteral and parenteral phases of trichinella infection in experimentally infected mice. Acta Trop. 201:105226. 
Huang, K, Shi, C, Min, J, Li, L, Zhu, T, 2019: Study on the mechanism of curcumin regulating lung injury induced by outdoor fine particulate matter (PM2.5). Mediat. Inflamm. 2019: 8613523.

Huang, L, Gebreselassie, NG, Gagliardo, LF, Ruyechan, MC, Lee, NA et al, 2014: Eosinophil-derived IL-10 supports chronic nematode infection. J. Immunol. 193:4178-87.

Hussein, A, Rashed, S, El Hayawan, I, El-Sayed, R, Ali, H, 2017: Evaluation of the anti-schistosomal effects of turmeric (Curcuma longa) versus Praziquantel in Schistosoma mansoni infected mice. Iran. J. Parasitol. 12, 4:587-96.

Hussein, Y, Lotfy, SA, Kamoun, EA, El-Moslamy, SH, Radwan, et al, 2021: Enhanced anti-cancer activity by localized delivery of curcumin form PVA/CNCs hydrogel membranes: Preparation and in vitro bioevaluation. Int. J. Biol. Macromol. 170:107-22.

Hwang, YP, Choi, JH, Yun, HJ, Han, EH, Kim, HG, et al, 2011: Anthocyanins from purple sweet potato attenuate dimethylnitrosamineinduced liver injury in rats by inducing Nrf2-mediated antioxidant enzymes and reducing $\mathrm{COX}_{-2}$ $\&$ iNOS expression. Food Chem. Toxicol. 49, 1: 93-9.

Ierna, MX, Scales, HE, Mueller, C, Lawrence, CE, 2009: Transmembrane tumor necrosis factor alpha is required for enteropathy and is sufficient to promote parasite expulsion in gastrointestinal helminth infection. Infect Immun.77, 9:3879-85.

Jiang S, Han J, Li T, Xin, Z, Zhiqiang Ma, Z, et al, 2017: Curcumin as a potential protective compound against cardiac diseases. Pharmacol. Res. 119:373-83.

Kang, SA, Park, MK, Park, SK, Choi, JH, Lee, DI, et al, 2019: Adoptive transfer of Trichinella spiralis-activated macrophages can ameliorate both Th1- and Th2-activated inflammation in murine models. Sci. Rep. 9, 1:6547-9.

Kim, SW, Roh, J and Park, CS, 2016: Immunohistochemistry for Pathologists: Protocols, Pitfalls, and Tips. J. Pathol. Transl. Med. 50, 6: 411-8.

Kuida, K, Zheng, TS, Na, S, Kuan, C, Yang, $\mathrm{D}$, et al, 1996: Decreased apoptosis in the brain and premature lethality in CPP32-deficient mice. Nature 384, 6607:368-72.

Lee, HY, Kim, SW, Lee, GH, Choi, MK, Chung, HW, et al, 2017: Curcumin and Curcuma longa $L$. extract ameliorate lipid accumulation through the regulation of the endoplasmic reticulum redox and ER stress. Sci. Rep. 7:6513-6.

Lee, J, Im, YH, Jung, HH, Kim, JH, Park, J O, et al, 2005: Curcumin inhibits interferon- $\alpha$ induced NF- $\mathrm{kB}$ and $\mathrm{COX}_{-2}$ in human A549 nonsmall cell lung cancer cells. Biochem. Biophys. Res. Communic. 334, 2:313-8.

Lee, KJ, Choi, CY, Chung, YC, Kim, YS, Ryu, SY, et al, 2004: Protective effect of saponins derived from roots of Platycodon grandiflorum on tert-butyl hydroperoxide-induced oxidative hepatotoxicity. Toxicol. Lett. 147:271-82.

Li, J, Meng, Z, Zhang, G, Xing, Y, Feng L, et al, 2015: N-acetylcysteine relieves oxidative stress and protects hippocampus of rat from radiation-induced apoptosis by inhibiting caspase-3 . Biomed. Pharmacother. 70:1-6.

Lin, LC, Hsu, SL, Wu, CL, Liu, WC, Hsueh, CM, 2011: Peroxisome proliferator-activated receptor gamma (PPAR gamma) plays a critical role in the development of TGF $\beta$ resistance of H460 cell. Cell Signal. 23, 10:1640-50.

Liu, H, Wang, C, Qiao, Z, Xu, Y, 2017: Protective effect of curcumin against myocardium injury in ischemia reperfusion rats. Pharm. Biol. 55, 1:1144-8.

Liu, L, Liu, YL, Liu, GX, Chen, X, Yang, K, et al, 2013: Curcumin ameliorates dextran sulfate sodium-induced experimental colitis by blocking STAT3 signaling pathway. Int. Immuno-pharmacol. 17, 2:314-20.

Liu, Y, Liu, Y, Huang, X, Zhang, J, Yang, L, 2019: Protective effects and mechanism of curcumin on myocardial injury induced by coronary microembolization. J. Cell. Biochem. 120, 4: 5695-703.

Lopes, MF, Costa-da-Silva, AC, DosReis, GA, 2014: Innate immunity to Leishmania infection: within phagocytes. Mediat. Inflamm. 2014: 754965.

Magalhaes, LG, Machado, CB, Morais, ER, Moreira, EB, Soares, CS, et al, 2009: In vitro schistosomicidal activity of curcumin against Schistosoma mansoni adult worms. Parasitol. Res. 104:1197-201.

Mahmoud, AM, Hozayen, WG, Hasan, IH, Shaban, E, Bin-Jumah, M, 2019: Umbelliferone ameliorates $\mathrm{CCl}$ 4-induced liver fibrosis in rats by upregulating PPAR $\gamma$ and attenuating oxidative stress, inflammation, and TGF- $\beta 1 / \mathrm{Smad} 3$ signaling. Inflammation, 42, 3:1103-16.

Mazala, DA, Novak, JS, Hogarth, MW, Nea- 
ring, M, Adusumalli, P, et al, 2020: TGF-betadriven muscle degeneration and failed regeneration underlie disease onset in a DMD mouse model. JCI Insight 5, 6:e135703.

Moghadamtousi, SZ, Abdul Kadir, H, Hassandarvish, P, Tajik, H, Abubakar, S, et al, 2014: A Review on antibacterial, antiviral, and antifungal activity of curcumin. Biomed. Res. Int. 2014:186864.

Mokbel, MK, Baiuomy, IR, Sabry, AA, Mohammed, MM, El-Dardiry, MA, 2020: In vivo assessment of the antischistosomal activity of curcumin loaded nanoparticles versus praziquantel in the treatment of Schistosoma mansoni. Sci. Rep.10, 1:15742.

Nada, SM, Mohammad, SM, Moad, HSF, EIShafey, MA, Ghandour, AMF, et al, 2018: Therapeutic effect of nigella sativa and ivermectin versus albendazole on experimental trichinellosis in mice. J. Egypt. Soc. Parasitol. 48, 1:85-92.

Nagajyothi, F, Zhao, D, Weiss, LM, Tanowitz, HB, 2012: Curcumin treatment provides protection against Trypanosoma cruzi infection. Parasitol. Res. 110:2491-9.

Nahar, S, Akhter, QS, 2018: Effect of Curcuma longa (Turmeric) on serum creatine kinase$\mathrm{MB}$ and troponin I in isoproterenol induced myocardial infarction in Wister albino rats. J. Bangladesh Soc. Physiol. 13, 2:47-53.

Neamatallah, T, El-Shitany, NA, Abbas, AT, Ali, SS, Eid, BG, 2018: Honey protects against cisplatin-induced hepatic and renal toxicity through inhibition of NF- $\kappa \mathrm{B}-$ mediated $\mathrm{COX}_{-2}$ expression and the oxidative stress dependent BAX/ Bcl-2/caspase-3 apoptotic pathway. Food Funct. 9, 7:3743-54.

Olson, J, 1999: Walsh and Hoyt's clinical neuro-ophthalmology. diseases caused by helminthic. Br. J. Ophthalmol. 83, 9:D1096-9.

Peat, J, Barton, B, 2005: Medical statistics: A Guide to Data Analysis and Critical Appraisal. $1^{\text {st }}$ Ed., Wiley-Blackwell.

Pérez-Arriaga, L, Mendoza-Magaña, ML, Cortés-Zárate, R, Corona-Rivera, A, Bobadilla-Morales, L, et al, 2006: Cytotoxic effect of curcumin on Giardia lamblia trophozoites. Acta. Trop. 98, 2:152-61.

Piera-Velazquez, S, Mendoza, F, Jimenez, S, 2016: Endothelial to mesenchymal transition (EndoMT) in the pathogenesis of human fibrotic diseases. J. Clin. Med. 5, 4:45-8.

Pozio, E, 2007: World distribution of Trichinella spp. infections in animals and humans. Vet.
Parasitol. 149, 1/2:3-21.

Pozio, E, Ludovisi, A, Pezzotti, P, Bruschi, F, Gómez-Morales, MA, 2019: Retrospective analysis of hospital discharge records for cases of trichinellosis does not allow evaluation of disease burden in Italy. Parasite 26:42-6.

Priotti, J, Codina, AV, Leonardi, D, Vasconi, MD, Hinrichsen LI et al, 2017: Albendazole microcrystal formulations based on chitosan and cellulose derivatives: Physicochemical characterization and in vitro parasiticidal activity in $T r$ ichinella spiralis adult worms. AAPS. Pharm. Sci. Tech. 18, 4:947-56.

Ricote, M, Huang, JT, Welch, JS, Glass, CK, 1999: The peroxisome proliferator-activated receptor (PPAR gamma) as a regulator of monocyte /macrophage function. J. Leukoc. Biol. 66, 5: 733-9.

Rohl, C, Lucius, R, Sievers, J, 2007: The effect of activated microglia on astrogliosis parameters in astrocyte cultures. Brain Res. 1129, 1:43-52.

Saad, AE, Ashour, DS, Abou, Rayia DM, Bedeer AE, 2016: Carbonic anhydrase enzyme as a potential therapeutic target for experimental trichinellosis. Parasitol. Res, 115, 6:2331-9.

Saad, HM, Safwat, O, El-Guindy, D, Raafat, R, Elgendy, D, Hasby, E, 2018: Biomolecular changes and cortical neurodegenerative lesions in Trichinella spiralis infected BALB/c Mice: A preliminary study elucidating a potential relationship between systemic helminthic infections \& idiopathic Parkinson's. Helminthologia 55, 4: 261-74.

Shaikh, SB, Bhandary, YP, 2020: Effect of curcumin on IL-17A mediated pulmonary AMP $\mathrm{K}$ kinase/cyclooxygenase-2 expressions via activation of NFKB in bleomycin-induced acute lung injury in-vivo. Int. Immunopharmacol. 85: 106676.

Shevach, EM, DiPaolo, RA, Andersson, J, Zhao, DM, Stephens, GL, et al, 2006: The lifestyle of naturally occurring CD4+ CD25+ Foxp$3+$ regulatory T cells. Immunol. Rev. 212:60-73. Shishodia, S, 2013: Molecular mechanisms of curcumin action: gene expression. Biofactors 39 , 1:37-55.

Stout-Delgado, HW, Getachew, Y, Rogers, T E, Miller, BC, Thiele, DL, 2007: The role of serpinb9/ serine protease inhibitor 6 in preventing granzyme B-dependent hepatotoxicity. Hepatology 46, 5:1530-40.

Tiwari, B, Pahuja, R, Kumar, P, Rath, SK, Gupta, KC, et al, 2017: Nanotized curcumin \& 
miltefosine, a potential combination for treatment of experimental visceral leishmaniasis. Antimicrob. Agents. Chemother. 61, 3:e01169-16.

Toms, $\mathrm{C}$ and Powrie, F, 2001: Control of intestinal inflammation by regulatory T cells. Microbes. Infect. 3, 11:929-35.

Varatharajalu, R, Garige, M, Leckey, LC, Gordillo, KR, Ruchi Shah, et al, 2016: Protective role of dietary curcumin in the prevention of the oxidative stress induced by chronic alcohol with respect to hepatic injury and antiatherogenic markers. Oxid. Med. Cell. Longev. 2016: 5017460 .

Venturiello, SM, Verzoletti, ML, Costantino, SN, Forastiero, MA, Roux, ME, 2007: Early pulmonary response in rats infected with Trichichinella spiralis. Parasitol. 134, Pt 2:281-8.

Waknine-Grinberg, J, McQuillan, J, Hunt, N, Ginsburg, H, et al, 2010: Modulation of cereb-

\section{Explanation of graphs}

Graph 1: Comparison of mean serum TNF- $\alpha \mathrm{Pg} / \mathrm{ml}$ among groups.

Graph 2: Comparison of mean serum TGF $-\beta \mathrm{Pg} / \mathrm{ml}$ among groups

Graph 3: Comparison of mean serum Troponine ug/m among groups

\section{Explanation of figures}

Fig.1: Inflammatory reparative response of lung tissue in infected T. spiralis \& treated groups. a- A prominent bronchial epithelial proliferation and mucin secretion (arrows) in infected group. b- Mild restoration of the bronchial epithelial number in the Cur-treated group. c- Complete restoration of bronchial epithelial number in Cur-Nano treated group (H\&E 200x). d- Marked BALT (asterisks) in infected group. e- Moderate BALT in Cur-treated group. f- Mild BALT in Cur-Nano treated group (H\&E 400x). g- Severe pleural and alveolar inflammatory infiltrate in infected group. h- Mild pleural and alveolar inflammatory infiltrate in Cur-treated group. i- No pleural \& alveolar inflammatory infiltrate in Cur-Nano treated group (H\&E 200x). j- Arginase expression in macrophages diffusely expressed in infected group. k-Moderate arginase expression in macrophages in Cur-treated group. 1- Mild arginase expression in macrophages in Cur-Nano treated (asterisks; IHC, 200x). m- Granzyme b expression in T cells diffusely expressed in infected group. $\mathrm{n}$ - Moderate granzyme b expression in T cells in Cur-trea-

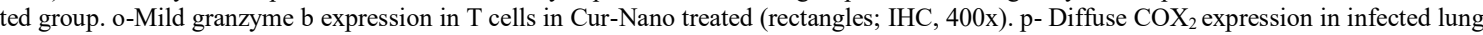
group. q- Moderate $\mathrm{COX}_{2}$ expression in lung on Cur-treated group. $\mathrm{r}$ - Mild $\mathrm{COX}_{2}$ expression in lung on Cur-Nano treated group (IHC, 400x). Fig. 2: Inflammatory reparative response of the liver tissue in infected $T$. spiralis \& treated groups. a- A prominent bile duct $\&$ ductular proliferation in infected group. b- Minimal ductal proliferation in Cur-treated group. c- No bile duct proliferation in Cur-Nano treated group (asterisks) (H\&E 200x). d- Marked portal tract rich eosinophilic infiltrate in infected group. e- Moderate portal tract inflammation in Cur group. f- Minimal portal tract inflammation in Cur-Nano treated group (rectangles; H\&E 400x). g- Moderate perivenular (zone III) inflammattion in infected group. h- Mild perivenular (zone III) inflammation in Cur-treated group. i- Minimal perivenular (zone III) inflammation in Cur-Nano treated group (H\&E 200x). j- Diffuse $\mathrm{COX}_{2}$ expression in inflammatory infiltrate on infected group. $\mathrm{k}$ - Moderate $\mathrm{COX}_{2}$ expression in the inflammatory infiltrate on infected group. 1-Mild $\mathrm{COX}_{2}$ expression in inflammatory infiltrate on infected group (IHC, 400x). m- Low PPAR expression in infected group. n- Mild PPAR expression in Cur-treated group. o- Strong PPAR expression in Cur-Nano treated group (IHC, 200x). p- Granzyme b expression in T cells diffusely expressed in the infected group. q- Moderate granzyme b expression in T cells in Cur-treated group. $r$ - Mild granzyme b expression in T cells in Cur-Nano treated (rectangles; IHC, 400x).

Fig. 3: Inflammatory reparative response of brain tissue in infected T. spiralis \& treated groups. a-A prominent thinning of dentate gyrus pyramidal layer (PL) \& neural loss in hippocampus in infected group. b- Mild thinning of dentate gyrus (PL) and neural loss in hippocampus in Cur-treated group. c- No thinning of dentate gyrus (PL) \& neural loss in hippocampus in Cur-Nano treated group (black bidirectional arrows) (H\&E 200x). d- Marked meningeal lymphocytic inflammation in infected group. e- Mild meningeal lymphocytic inflammation in Cur-treated group. f- No meningeal lymphocytic inflammation in Cur-Nano treated group (arrows; H\&E, 200x). g- Marked degenerative neural changes (arrow) and numerous Lewy's bodies (asterisks) in infected group. h- Moderate degenerative neural changes (arrow) and numerous Lewy's body (asterisks) in the Cur-treated group i- Mild degenerative neural changes (arrow) and numerous Lewy's body (asterisks) in Cur-Nano treated group (H\&E 200x). j- Strong diffuse GFAP IHC expression in the infected group. k- Moderate GFAP IHC expression in Cur-treated group. 1- Mild GFAP IHC expression in Cur-Nano treated group (IHC, 200x). m- Strong caspase 3 expression in infected group. n- Moderate caspase 3 expression in Cur-treated group. o- Mild caspase 3 expression in Cur-Nano treated group (arrows; IHC, 200x) Fig. 4: Inflammatory reparative response of heart tissue in infected T. spiralis \& treated groups. a- Marked degenerative changes in heart muscle with fat between infected group. b- Moderate degenerative changes in Cur-treated group. c- Mild degenerative changes in Cur-Nano treated group (arrows; H\&E, 200x). d- Strong caspase 3 expression in infected group. e- Moderate caspase 3 expression in Cur-treated group. $\mathrm{f}$ - Mild caspase 3 expression in Cur-Nano treated group (arrows; IHC, 200x). 

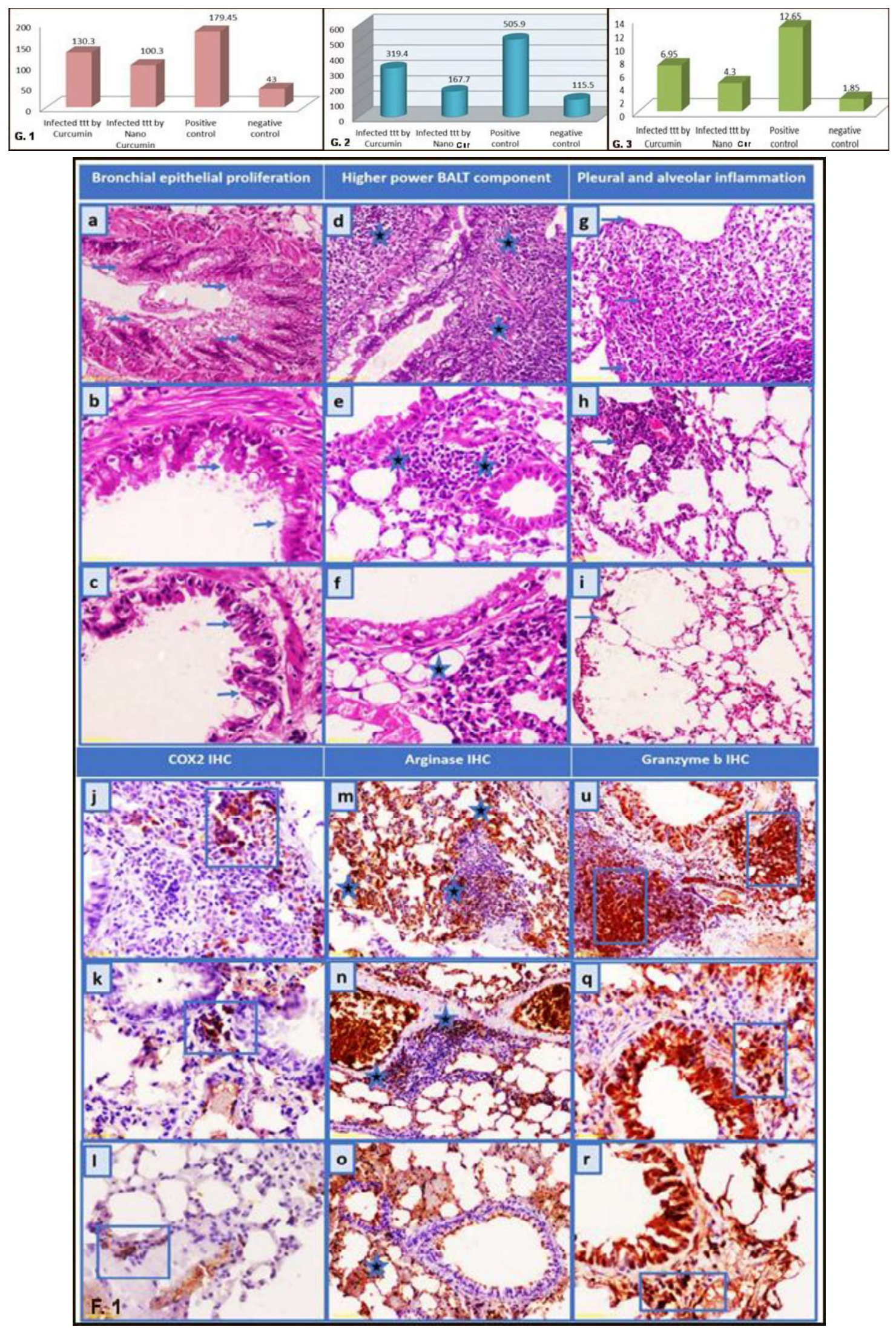


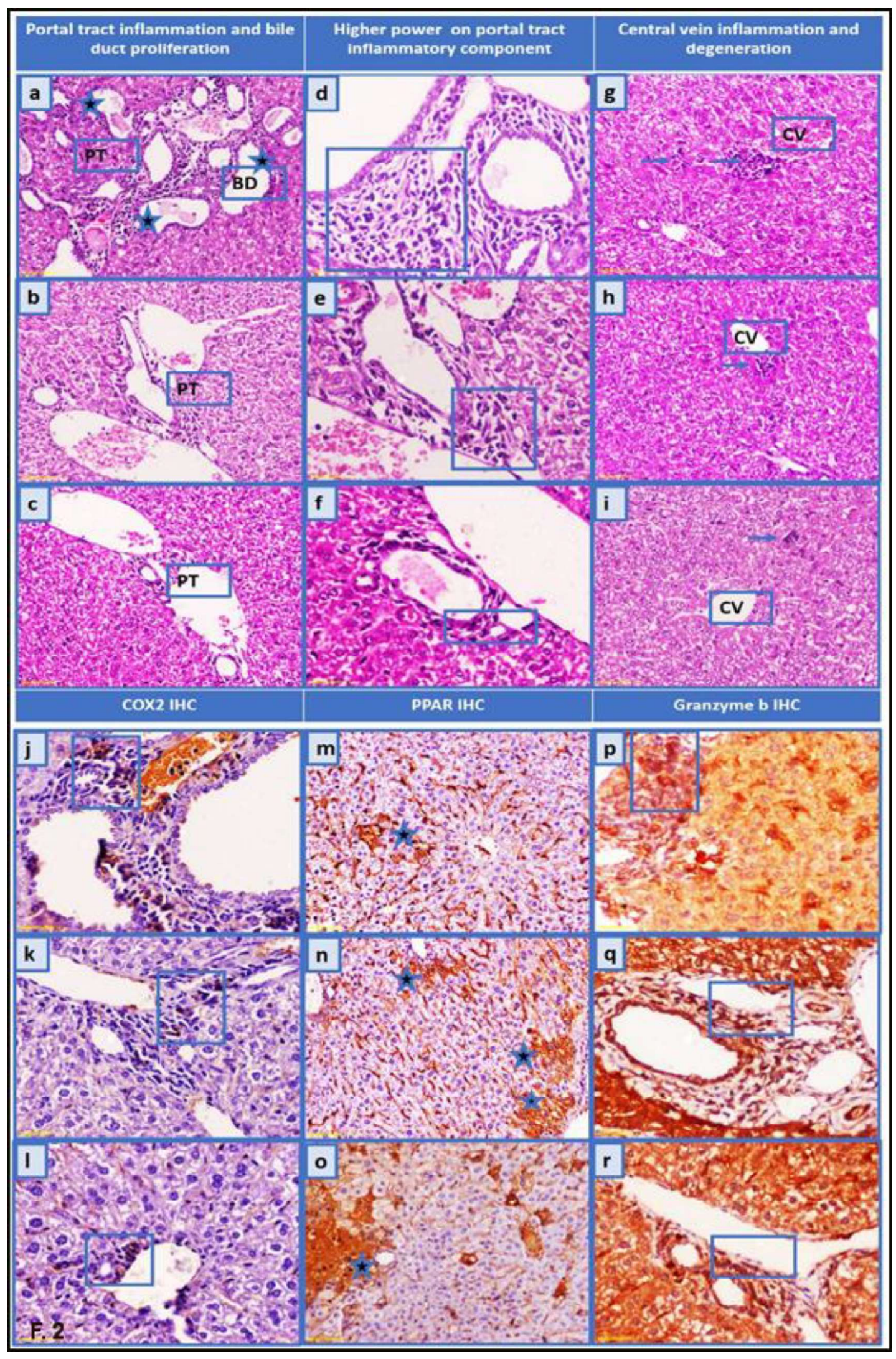




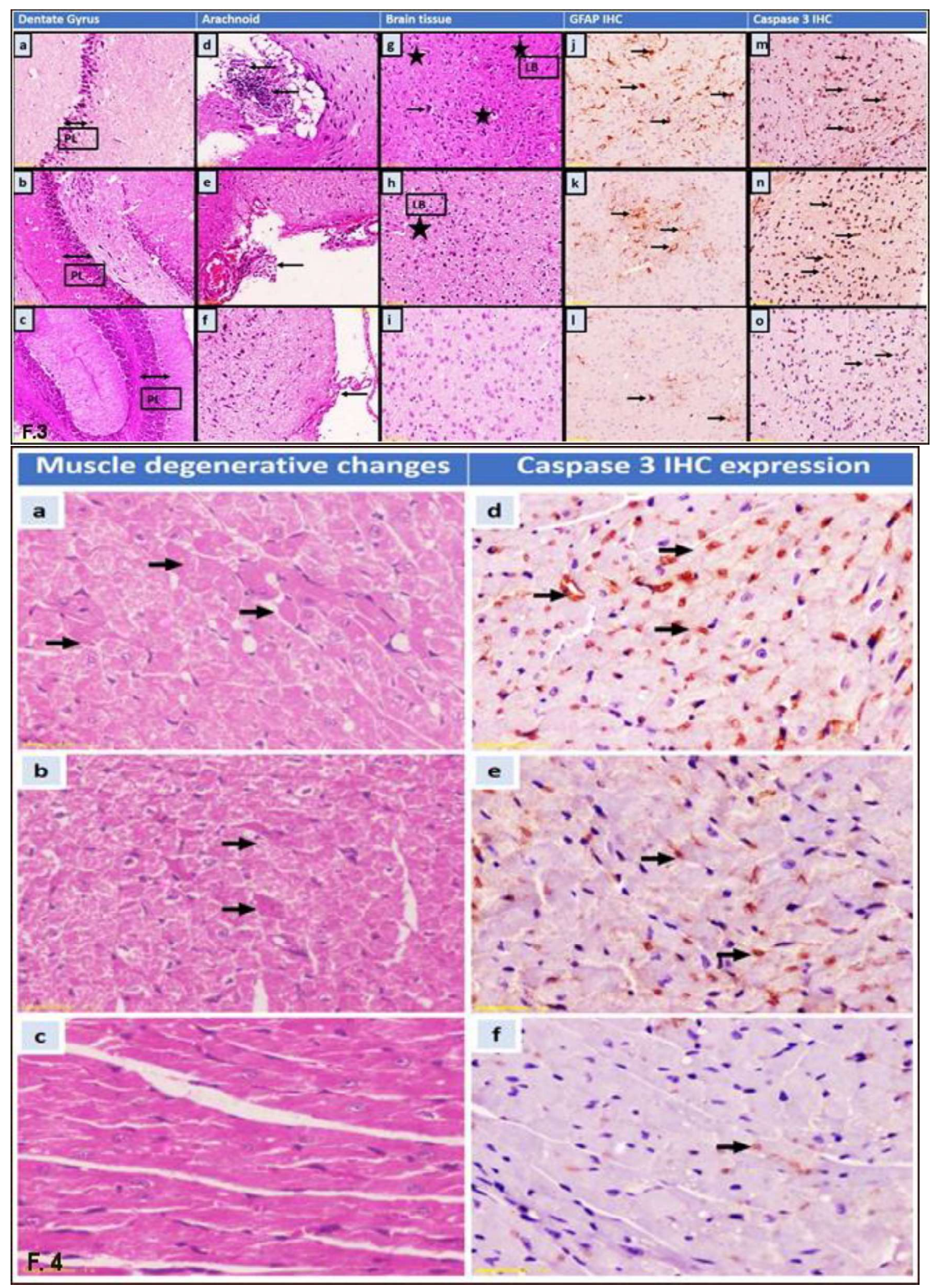

